\title{
INFLUÊNCIA DO TRATAMENTO TÉRMICO PÓS- SOLDAGEM NA MICROESTRUTURA E DUREZA DA ZTA DO AÇO 9\%NI PARA APLICAÇÃO OFFSHORE
}

\section{INFLUENCE OF POST-WELDING HEAT TREATMENT ON MICROSTRUCTURE AND HARDNESS OF 9\% NI STEEL HAZ FOR OFFSHORE APPLICATION}

\author{
K. D. P. CRUZ ${ }^{1}$, P. E. M. MINEIRO² \\ ${ }^{1}$ Universidade Federal do Rio de Janeiro, Departamento de Engenharia Metalúrgica e de \\ Materiais, Brasil \\ ${ }^{2}$ Universidade Federal do Rio de Janeiro, Departamento de Engenharia Metalúrgica e de \\ Materiais, Brasil \\ E-mail: kdebora.cruz@poli.ufrj.br
}

article info

Article history:

Received 2017-09-04

Accepted 2017-11-20

Available online 2017-12-20
PALAVRAS-CHAVE: Soldagem de revestimento; Zona Térmicamente Afetada (ZTA); Aço 9\% Níquel; Tratamento Térmico Pós-Soldagem.

KEYWORDS: Cladding; Heat Affected Zone (HAZ); 9\% Nickel Steel; Post Welding Heat Treatment.

RESUMO: No Pré-sal, o sistema de reinjeção de CO2 aumenta a produtividade dos poços e atinge a temperatura de $-95^{\circ} \mathrm{C}$ na rápida descompressão em caso de falha. Como o sistema está sujeito a condições altamente corrosivas, a soldagem de revestimento dos tubos de aço 9\% Ni com superliga de níquel por processo GTAW está sendo estudada. Segundo estudos prévios, o tratamento térmico pós-soldagem (TTPS) é recomendado devido a alta dureza da ZTA. Porém, estudos conforme a norma ASTM A333 grau 8 não atingiram os niveis desejados de dureza. Neste trabalho foram analisados TTPS's em distintas condições de temperatura e tempo, procurando identificar a que melhor atende à aplicação. Após 40 condições de tratamentos testadas, ensaios de dureza e caracterização por microscopia, verificou-se que a mínima dureza ocorre na condição de duas camadas de revestimento tratada à $600^{\circ} \mathrm{C}$ por $4 \mathrm{~h}$, devido à microestrutura similar ao metal base composta por matriz ferrítica com austenita reversa nos contornos de grãos.

\begin{abstract}
On Pre-salt fields, the system for re-injection of CO2 increases the productivity of the wells and reaches $-95^{\circ} \mathrm{C}$ on quick decompression at a failure event. As the system is subjected to highly corrosive conditions, cladding GTAW welds of 9\% Ni steel pipes with nickel-based super alloy is being studied. According to previous studies, post-weld heat treatment (PWHT) is recommended due to the high hardness on HAZ. However, studies according to ASTM A333 grade 8 did not reach the desired levels of hardness. In this work, PWHT's were analyzed for different temperature and time conditions to identify the one that best suits the application. After 40 treatment conditions, hardness testing and microscopic characterization, it was verified that the minimum hardness occurs for the double layer coating condition and post-weld heat treatment at $600^{\circ} \mathrm{C}$ for $4 \mathrm{~h}$, due to a similar microstructure to the base metal, which is composed of ferritic matrix with reverse austenite at grain boundaries.
\end{abstract}

\section{INTRODUÇÃO}

A exploração e produção de petróleo nos campos do Pré-sal levou a inovações como o sistema de reinjeção de $\mathrm{CO} 2$, que aumenta a produtividade dos poços e pode chegar a 
temperatura de $-95^{\circ} \mathrm{C}$ na rápida descompressão em caso de falha do poço. Por isso, um aço de alta tenacidade em baixas temperaturas com o teor de níquel de aproximadamente $9 \% \mathrm{em}$ peso tem sido adotado para esta aplicação criogênica. No entanto, este sistema está sujeito a substâncias altamente corrosivas, como ácido carbônico e ácido sulfídrico, presentes na mistura de $\mathrm{CO} 2$ úmido reinjetado. Assim, a soldagem de revestimento dos tubos deste aço com superliga de níquel, resistente à corrosão, por processo GTAW está sendo estudada.

A norma NACE MR0175 requer dureza da ZTA e metal base inferior a $250 \mathrm{HV} 10$ para a qualificação a este ambiente de corrosão ácida. Estudo recente aponta que na condição soldada a ZTA apresenta estrutura martensítica-bainítica na zona de grãos grosseiros e finos com dureza acima de $250 \mathrm{HV}$, tornando o tratamento térmico após soldagem necessário. Estudos posteriores sobre tratamento térmico das juntas soldadas segundo padrões da norma ASTM ainda não atingiram os níveis requeridos de dureza. Sendo assim, o objetivo deste trabalho é analisar diferentes condições de temperatura e tempo (além daquelas normalizadas) de tratamento térmico e sua influência metalúrgica, identificando aquela que melhor atende à aplicação.

\section{MATERIAIS E MÉTODOS}

Amostras de tubos de aço 9\% Ni da empresa Vallourec, revestido com uma e duas camadas de superliga de níquel (inconel 625) foram submetidas a tratamentos térmicos nos tempos de $2 \mathrm{~h}, 3 \mathrm{~h}, 4 \mathrm{~h}$ e $5 \mathrm{~h}$, e temperaturas $535 \mathrm{C}^{\circ}, 550^{\circ} \mathrm{C}, 565^{\circ} \mathrm{C}, 585^{\circ} \mathrm{C}$ e $600^{\circ} \mathrm{C}$ (Tabela 1 ), totalizando 40 amostras, além de 2 amostras como soldadas. Foram feitos ensaios de microdureza Vickers $(\mathrm{HV} 0,1)$ e tratamentos estatísticos de resultados das microdurezas. Logo, obtivemos a melhor condição de tratamento térmico, que foi caracterizada por microscopia óptica e eletrônica, com a utilização do reagente nital 5\%, e comparada com a caracterização da condição mais crítica.

Tabela 1 - Temperatura e tempos utilizados para a realização dos tratamentos térmicos.

\begin{tabular}{|c|c|c|c|c|c|}
\hline & \multicolumn{4}{|c|}{ Tempo (h) } \\
\hline & & 2 & 3 & 4 & 5 \\
\hline \multirow{5}{*}{ 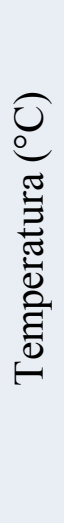 } & 535 & Amostra 1 & Amostra 2 & Amostra 3 & Amostra 4 \\
\hline & 550 & Amostra 5 & Amostra 6 & Amostra 7 & Amostra 8 \\
\hline & 568 & Amostra 9 & Amostra 10 & Amostra 11 & Amostra 12 \\
\hline & 585 & Amostra 13 & Amostra 14 & Amostra 15 & Amostra 16 \\
\hline & 600 & Amostra 17 & Amostra 18 & Amostra 19 & Amostra 20 \\
\hline
\end{tabular}




\section{RESULTADOS E DISCUSSÃO}

\subsection{Microdureza Vickers}

Os resultados de microdureza Vickers para as condições como soldadas apresentaram valores bastante elevados para qualificação em ambiente ácido, corroborando com Reddo (2015) e Passos (2016), sobre a necessidade de tratamento térmico para redução de dureza. Os ensaios de microdureza também revelaram que o ciclo térmico da segunda camada contribuiu para significativa redução de dureza em relação à condição de camada única tanto no centro dos passes quanto nos interpasses (Figuras 1 e 2). Os passes de segunda camada de revestimento produzem um efeito de revenimento da microestrutura da ZTA, sendo as durezas médias da ZTA das condições soldadas de uma e duas camadas, respectivamente, 352 e $289 \mathrm{HV}$. Todas as condições termicamente tratadas apresentaram dureza da ZTA menor que a respectiva como soldada, com a condição tratada em $4 \mathrm{~h}$ a $600^{\circ} \mathrm{C}$ apresentando a menor dureza média (255 HV) e menor dureza máxima (285 HV) na ZTA (Figuras 3 e 4).

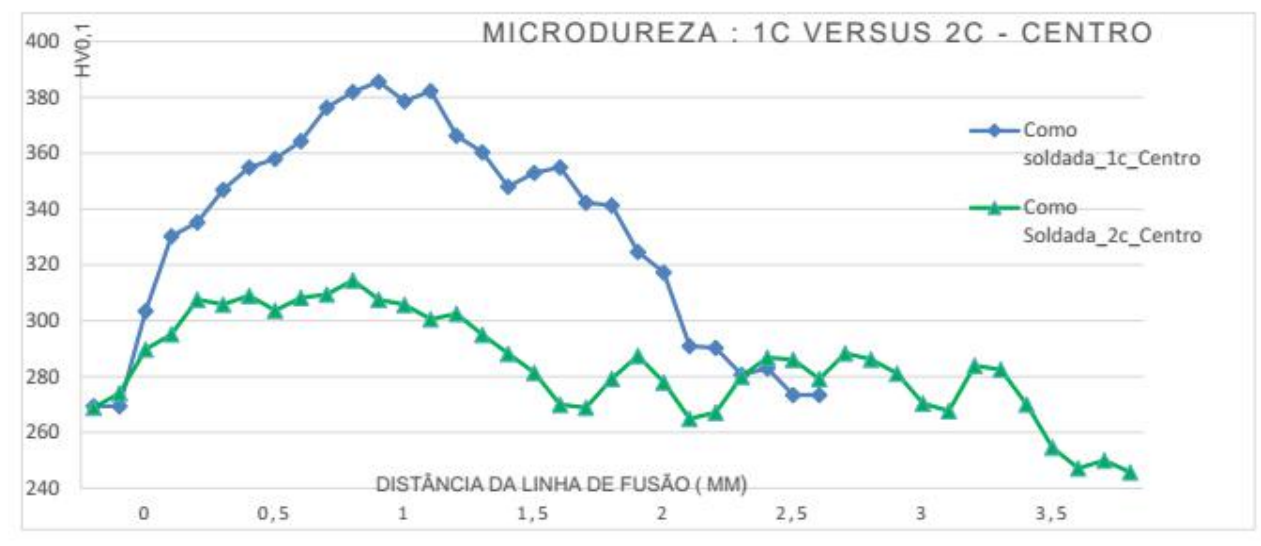

Figura 1- Perfil de dureza da ZTA de uma camada versus duas camadas no centro de um passe.

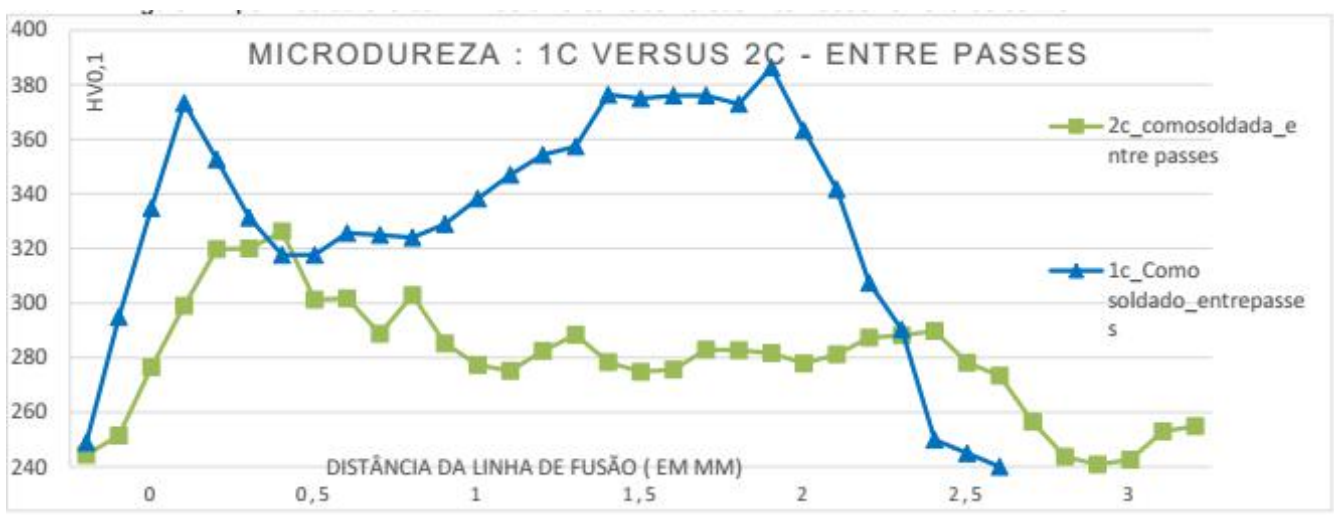

Figura 2 - Perfil de dureza da ZTA de uma camada versus duas camadas entre dois passes. 


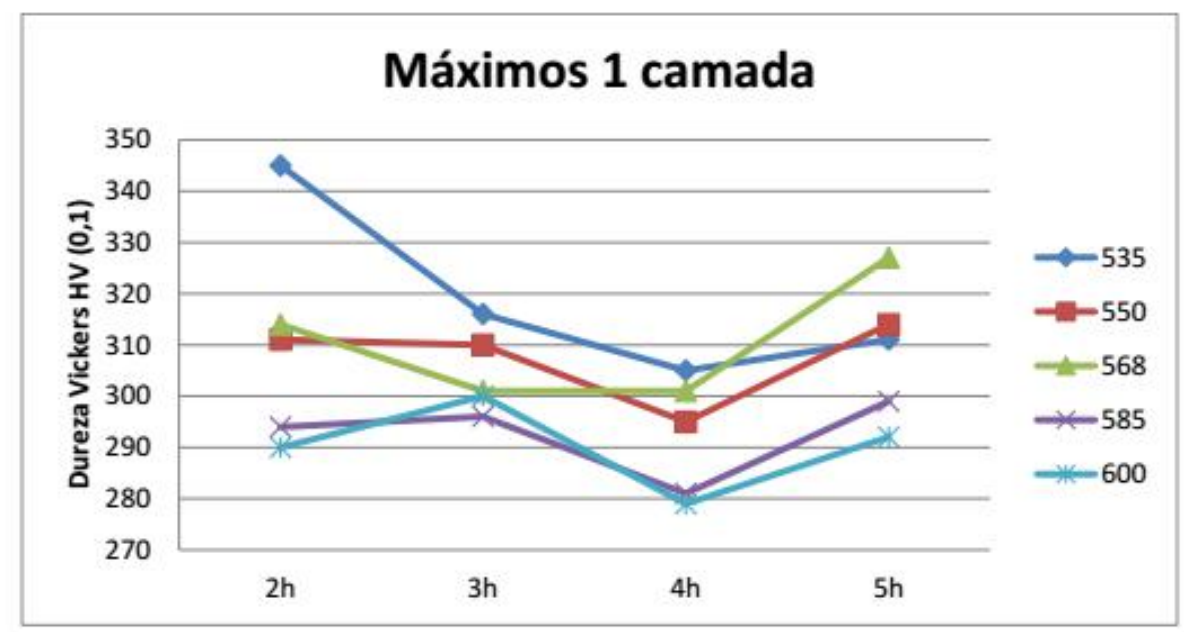

Figura 3 - Gráfico de durezas máximas em diferentes tempos e temperaturas para amostras com uma camada de revestimento.

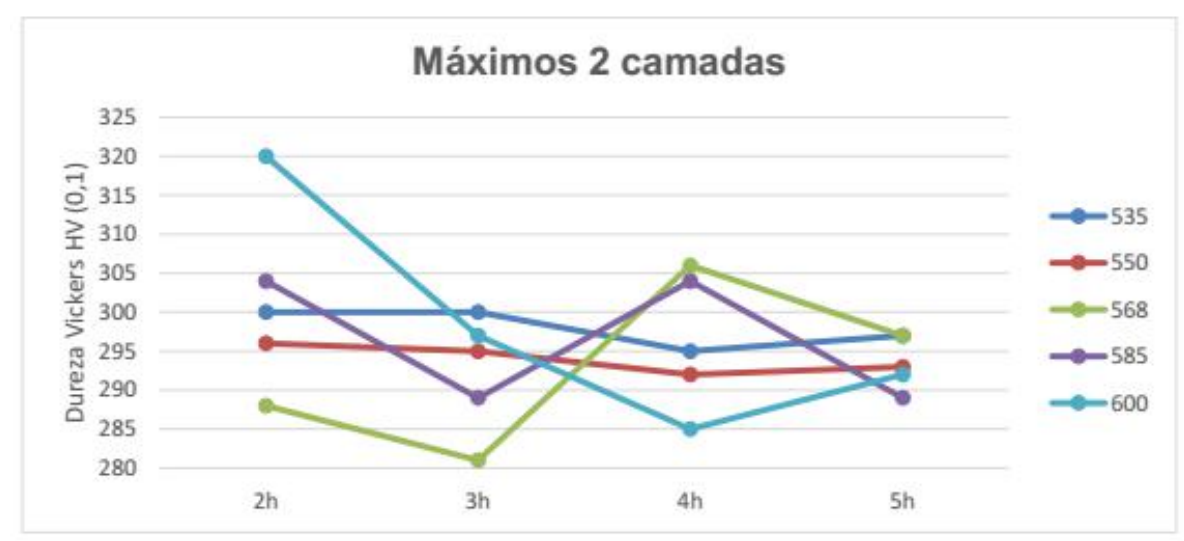

Figura 4 - Gráfico de durezas máximas em diferentes tempos e temperaturas para amostras com 2 camadas de revestimento.

\subsection{Microscopia Óptica}

No caso da amostra de uma camada, a máxima dureza na Zona de Grão Grosseiros (ZGG) ocorre numa zona de transição para a Zona de Grãos Finos (ZGF) em que se combinam os fatores de formação martensítica e redução do tamanho de grão, conforme Figura 5. Na ZGF, há alto grau de refino da microestrutura com contornos de grãos praticamente não resolvíveis, o que justifica a dureza elevada. A Zona Intercrítica (ZIC) apresenta maior crescimento de grãos com contornos escurecidos, provavelmente em função da precipitação de fases como a austenita retida nos contornos durante o resfriamento a partir do campo intercrítico, conforme Rodrigues (2016) e Zeemann et al (2014). Nas Figuras 6, 7 e 8 é possível observar com maiores detalhes a microestrutura de cada zona da ZTA. 


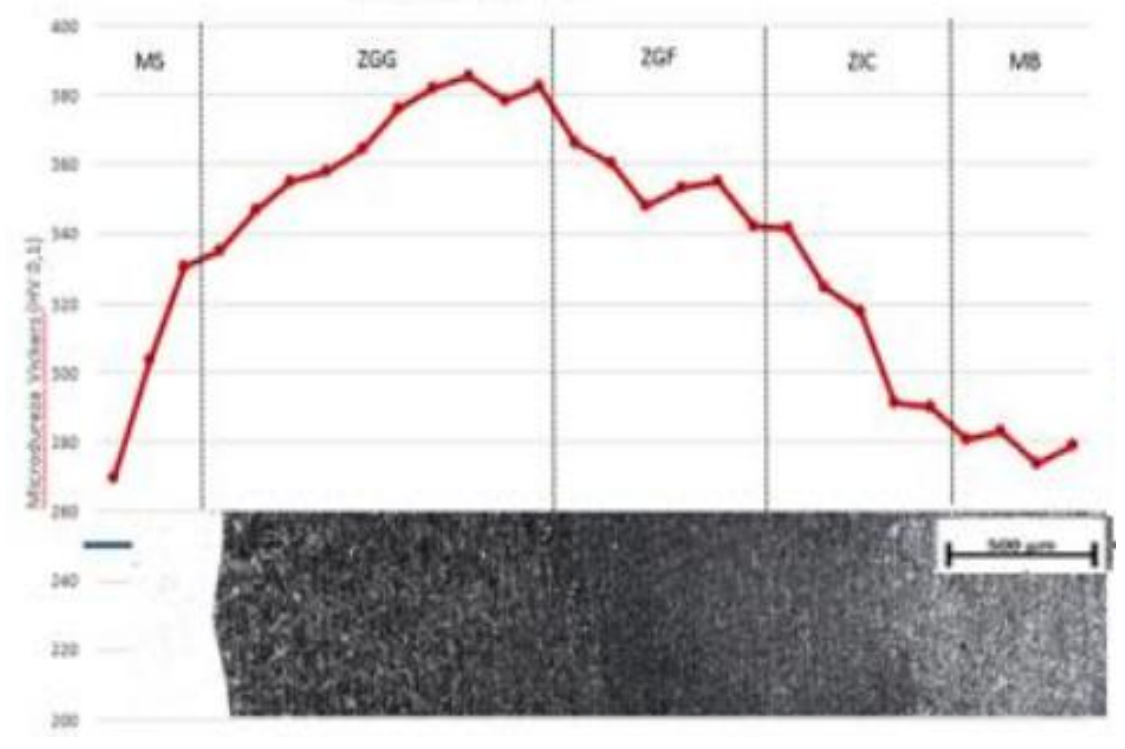

Figura 5 - Amostra como soldada (1 camada): dureza média de $352 \pm 33 \mathrm{HV} . \mathrm{MS}=$ metal de solda; $\mathrm{MB}=$ metal base. Aumento de 200x.

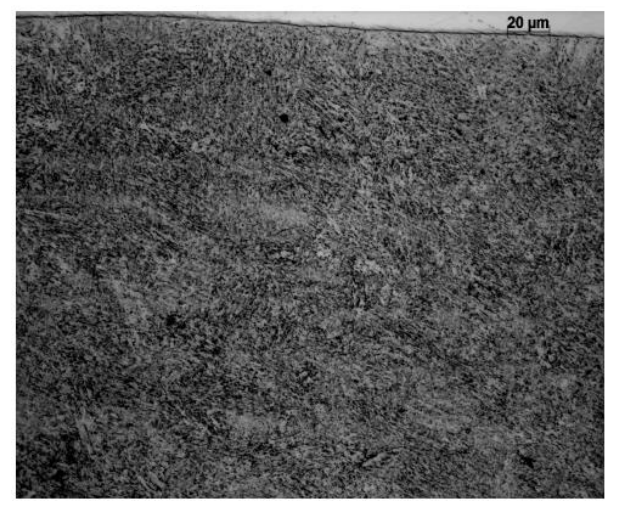

Figura 6 - ZGG: Microestrutura martensítica de ripas. Aumento de500x.

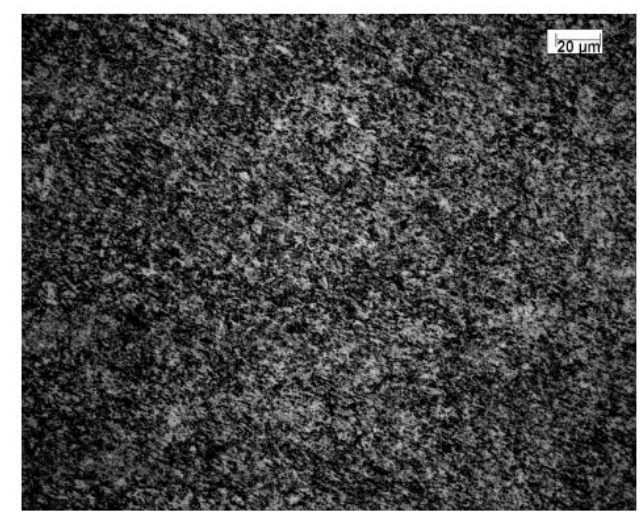

Figura 7 - ZGF: Microestrutura bem refinada. Aumento de 500x. 


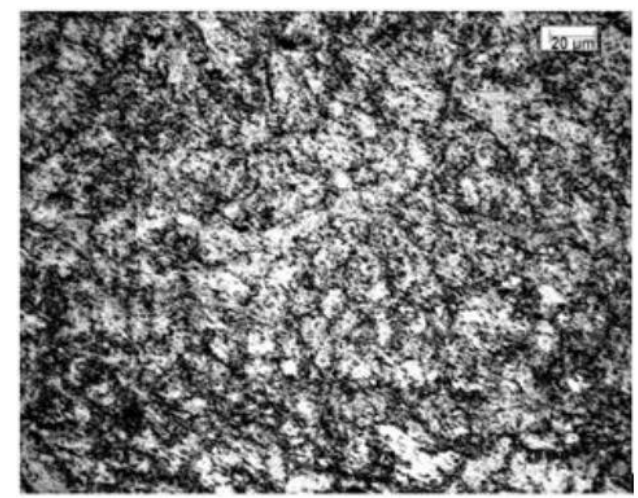

Figura 8 - ZIC: Grãos ferríticos com contornos de grãos escurecidos. Aumento:500x.

No caso da amostra como soldada de duas camadas (Figura 9), os valores de dureza são elevados na ZGG devido à formação martensítica de ripas, mas houve formação bainítica, o que pode ter contribuído para redução de dureza em relação à condição de uma camada não tratada. Na ZGF, também foi identificada microestrutura martensítica com alguma bainita contribuindo para queda da dureza, numa matriz bastante refinada com contornos de grãos não-resolvíveis no microscópio óptico. Na ZIC, foi caracterizada formação ferrítica com menos regiões escurecidas que na ZGF. Nas Figuras 10, 11 e 12 é possível observar com maiores detalhes a microestrutura de cada zona da ZTA.

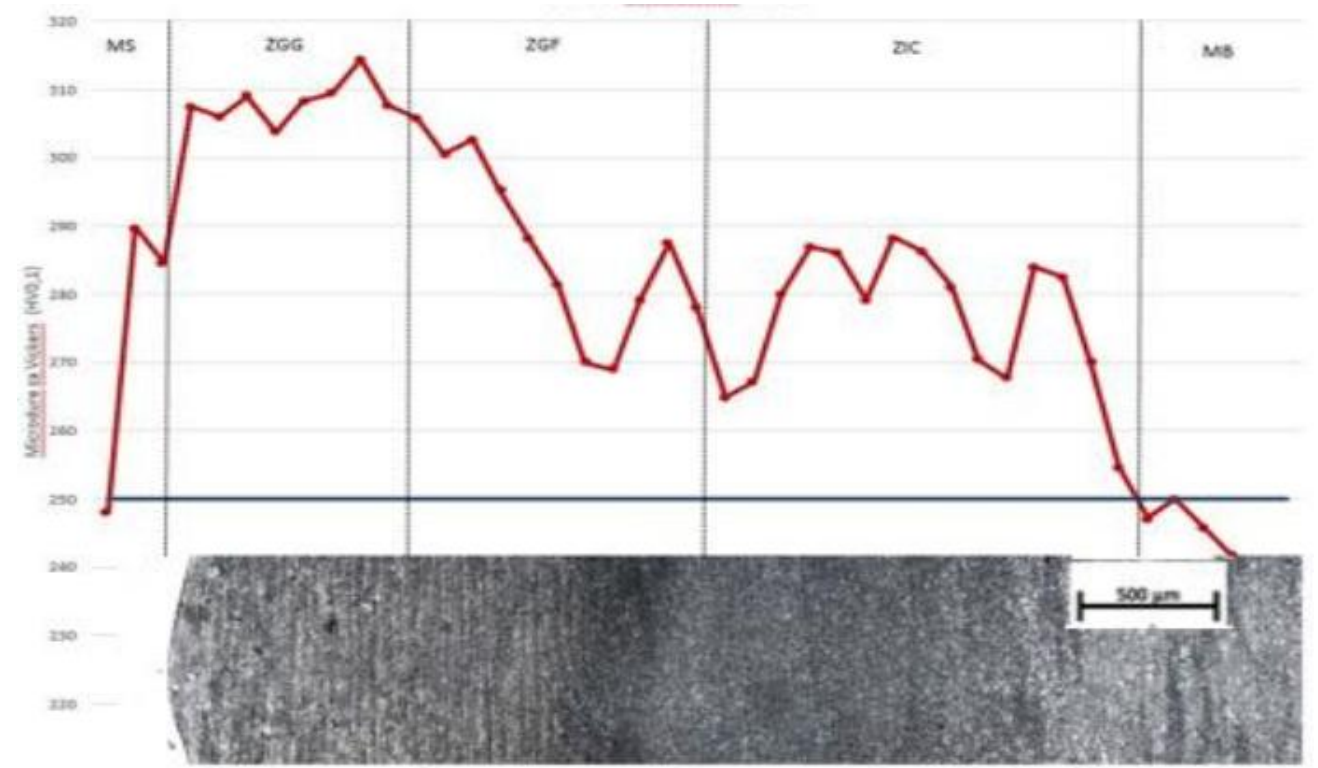

Figura 9 - Amostra como soldada ( 2 camadas): dureza média de $289 \pm 18 \mathrm{HV}$. Aumento de 200x. 


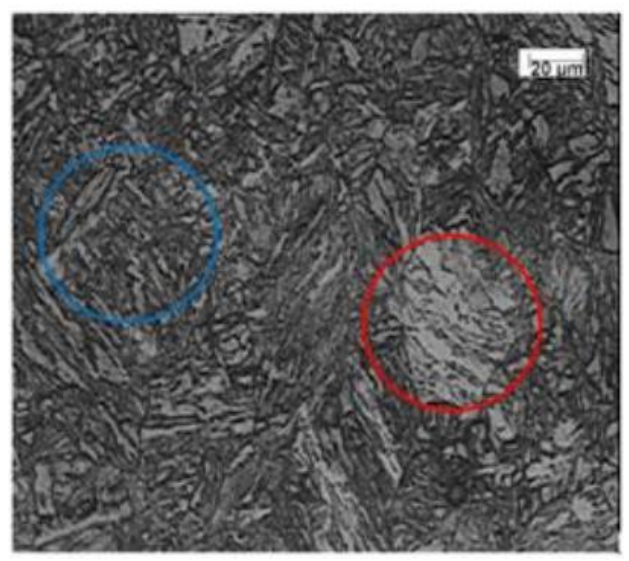

Figura 10 - ZGG: Microestrutura martensítica de ripas (em azul) com alguma bainita (em vermelho). Aumento de 500x.

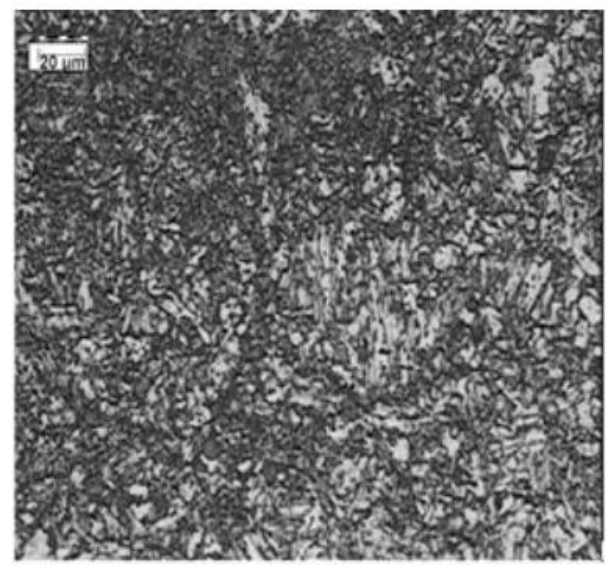

Figura 11 - ZGF: Microestrutura refinada martensítica com alguma bainita (em vermelho). Aumento de 500x.

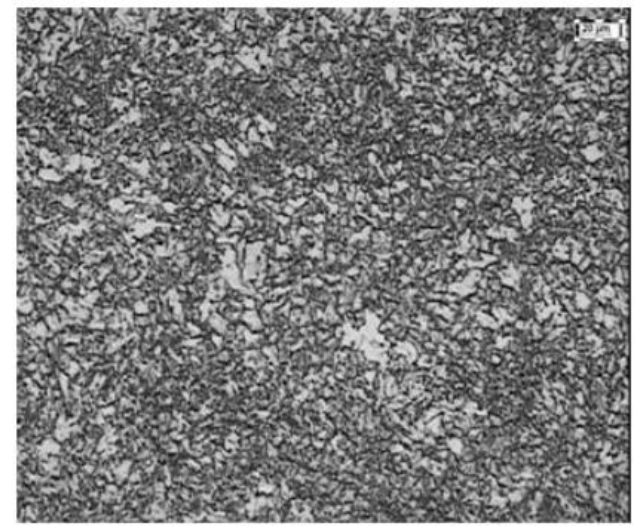

Figura 12 - ZIC: Matriz ferrítica com refinamento de grãos (regiões escurecidas).

Para altas temperaturas e longos tempos de tratamento térmico, houve significativo 
revenimento da martensita com produção de estrutura ferrítica e seu crescimento de grão na ZGG, reduzindo a dureza (Figuras 16 e 20). As fases escuras presentes podem ser agregados de ferrita com carbetos e/ou austenita. Por outro lado, nas ZGF (Figuras 17 e 21) e ZIC (Figuras 18 e 22), apesar do escurecimento das imagens devido à possível precipitação de novas fases, a intensa formação ferrítica contribuiu para efetiva redução de dureza, atingindo valores inferiores a $250 \mathrm{HV}$ no caso de duas camadas (Figuras 15 e 19).

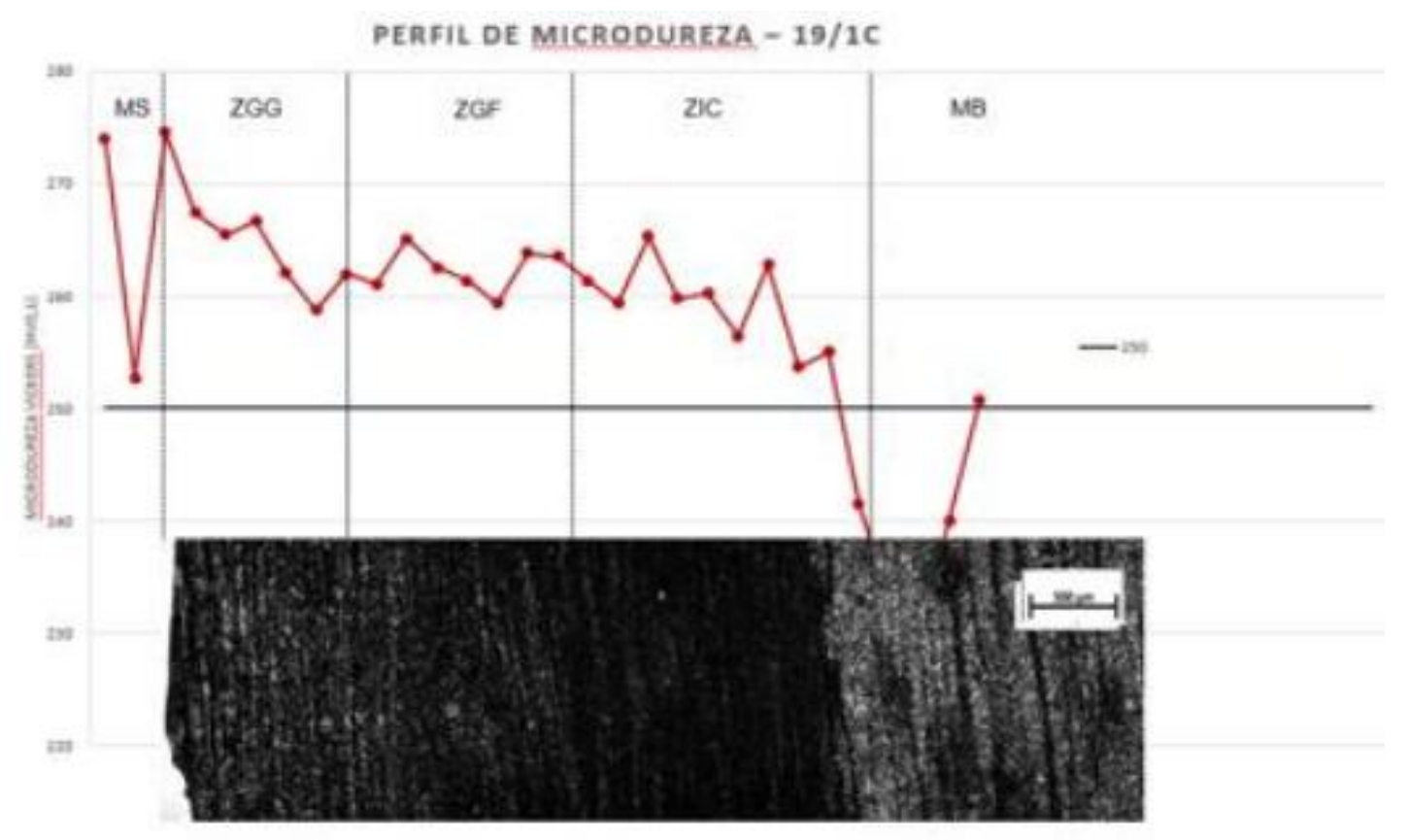

Figura 13 - amostra termicamente tratada à $600^{\circ} \mathrm{C}$ por $4 \mathrm{~h}$ (uma camada de revestimento): dureza média de $261 \pm 17 \mathrm{HV}$. Aumento de 500x.

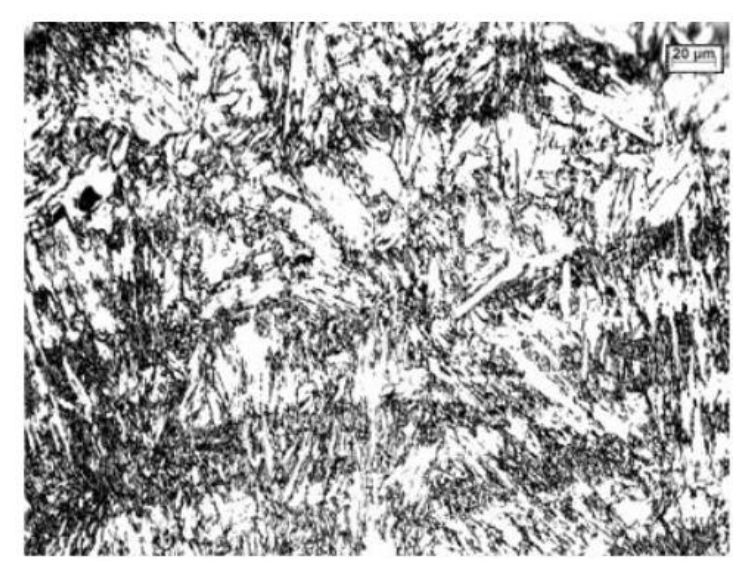

Figura 14 - ZGG: Microestrutura ferrítica proveniente de revenimento da martensita (uma camada de revestimento). Aumento de 500x. 


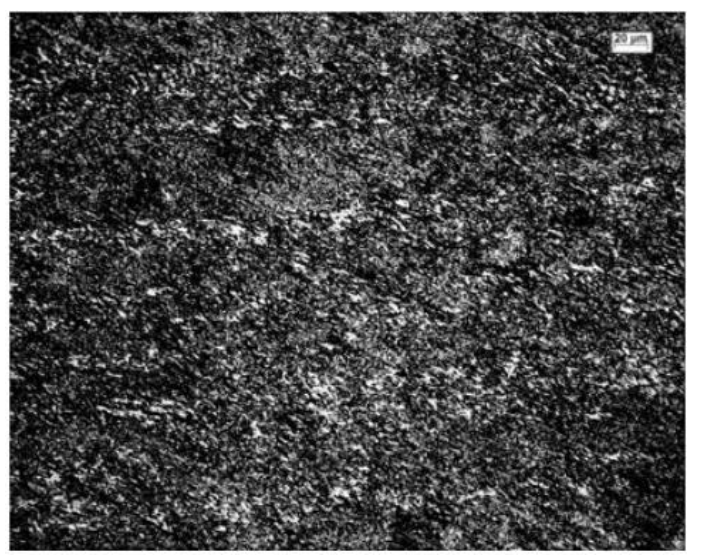

Figura 15 - ZGF- Microestrutura ferrítica bastante refinada (escurecimento da imagem) (uma camada de revestimento). Aumento de 500x.

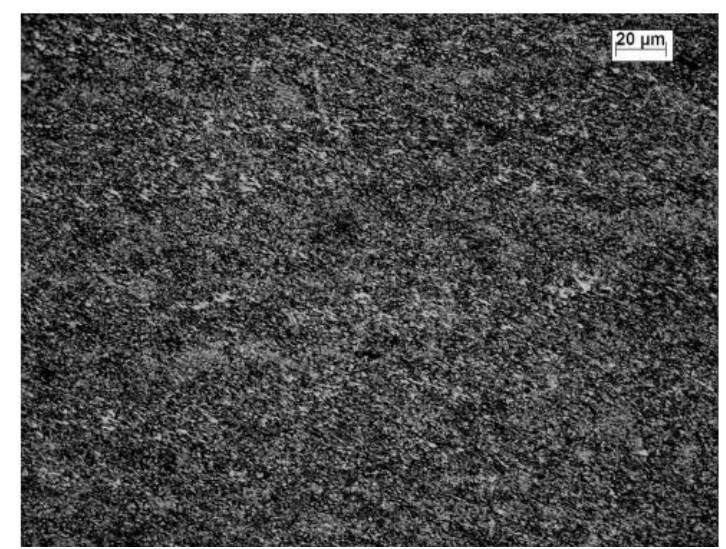

Figura 16 - ZIC: Matriz ferrítica bem refinada (uma camada de revestimento). Aumento de 500x.

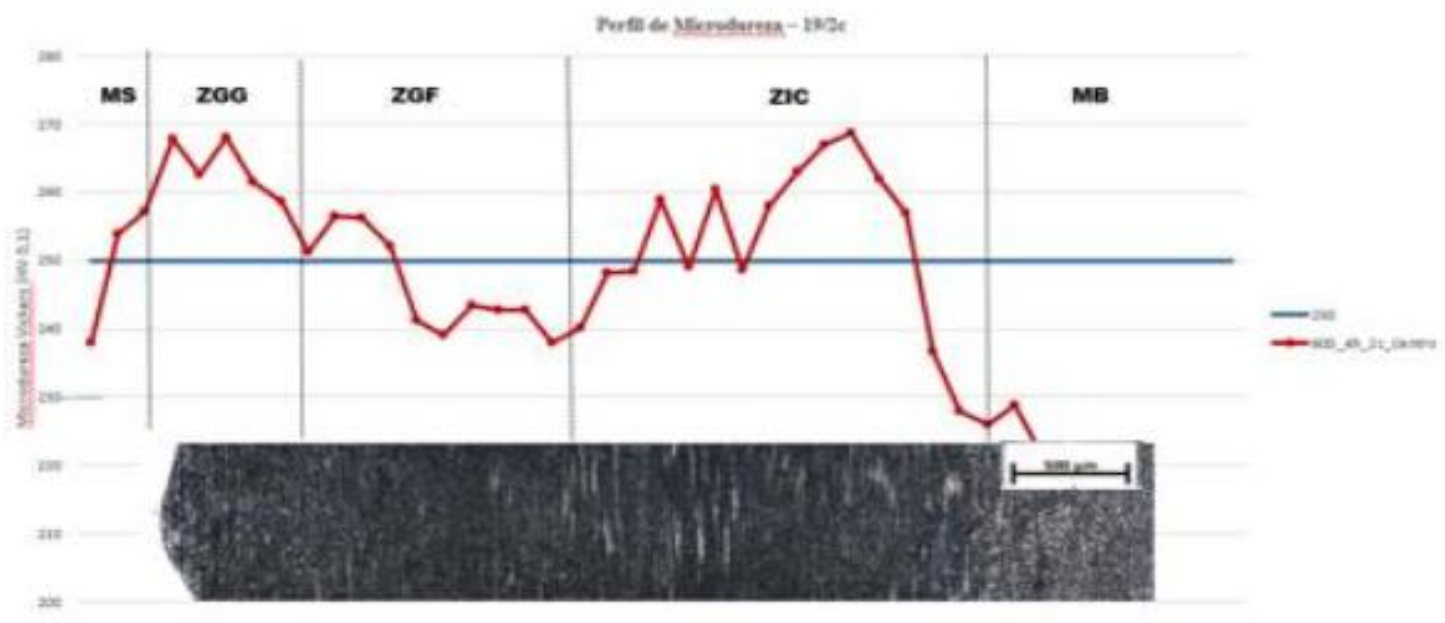

Figura 17 - Amostra termicamente tratada $600^{\circ} \mathrm{C}$ por $4 \mathrm{~h}$ (duas camadas de revestimento): dureza média de $254 \pm 13 \mathrm{HV}$. Aumento de 200x. 


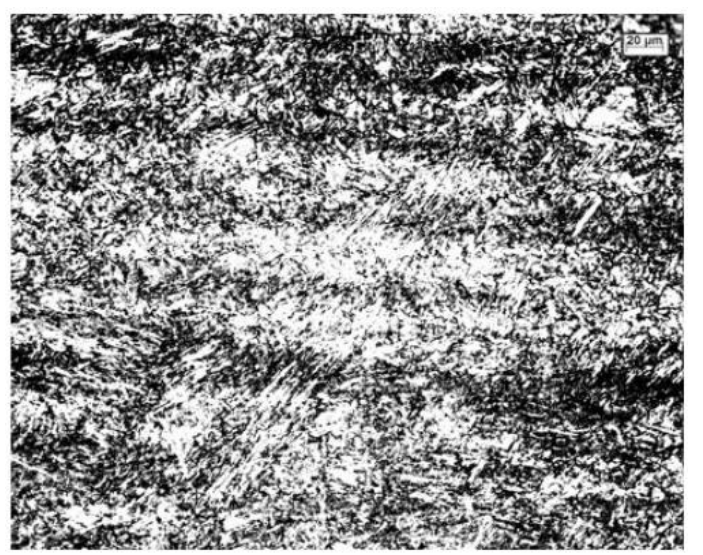

Figura 18 - ZGG - Grãos ferríticos alongados em função do revenimento de martensita (duas camadas de revestimento). Aumento de 500x.

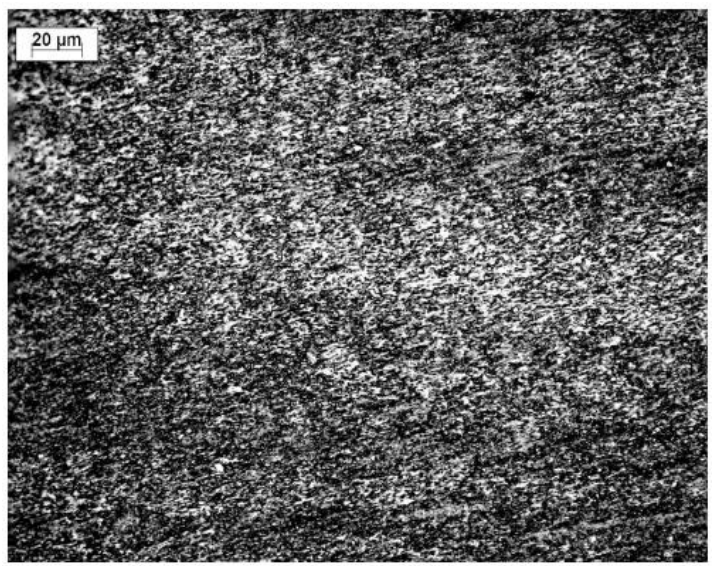

Figura 19 - ZGF: Microestrutura ferrítica refinada (duas camadas de revestimento). Aumento de 500x.

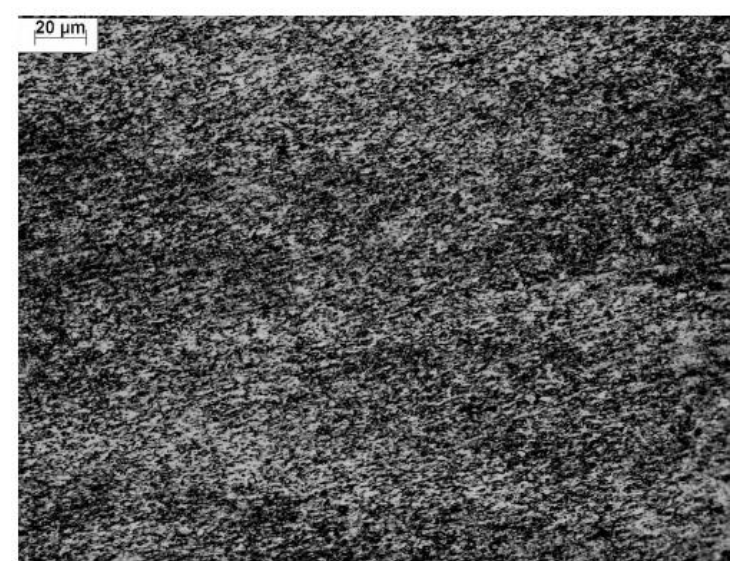

Figura 20-ZIC: Microestrutura ferrítica refinada (duas camadas de revestimento). Aumento de 500x. 


\subsection{Microscopia Eletrônica de Varredura}

A análise por microscopia eletrônica de varredura (MEV) permitiu caracterizar, confirmar e detectar a presença das fases ferrita, martensita de ripas, martensita revenida, bainita, precipitados e austenita. Ratificando os resultados de microscopia óptica, a caracterização via MEV apontou a presença de pacotes de martensita de ripas dentro de grãos de austenita prévia na ZGG na condição como soldada, tanto para uma quanto para duas camadas (Figuras 21 e 22).

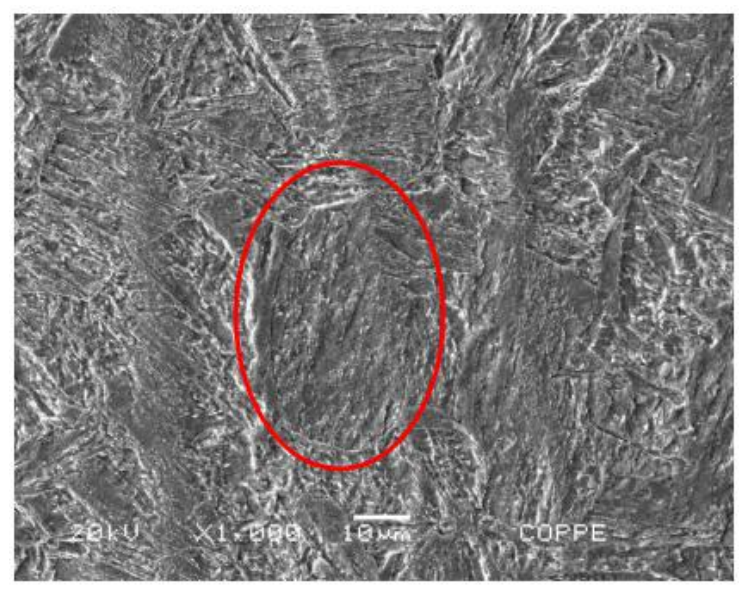

Figura 21 - Estrutura de martensita em ripas na condição como soldada com uma camada de revestimento.

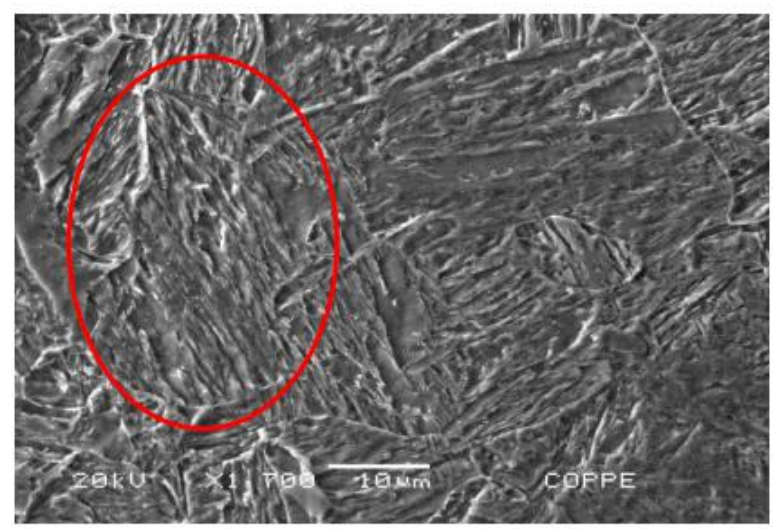

Figura 22 - Estrutura de martensita em ripas na ZGG da condição como soldada com duas camadas de revestimento.

Na ZTA de grãos finos da condição soldada de uma camada, a microestrutura bastante refinada não resolvível por microscópio óptico apresenta finas ripas de martensita da ordem de 1 micrômetro, apenas identificadas em aumentos elevados de 10000 vezes (Figura 23). 


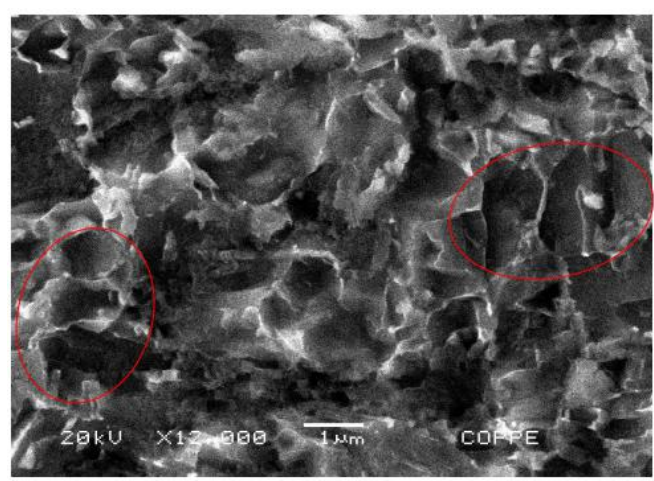

Figura 23 - Finas ripas de martensita na ZGF da condição como soldada com uma camada.

Na condição de duas camadas, a zona de grãos finos apresenta estrutura de grãos finos menos refinada que a de uma camada, contendo finas ripas de martensita já resolvíveis em aumentos da ordem de 5000 vezes (Figura 24). Foi identificada bainita inferior na microestrutura de grãos finos, corroborando com os resultados de microscopia óptica (Figura 25).

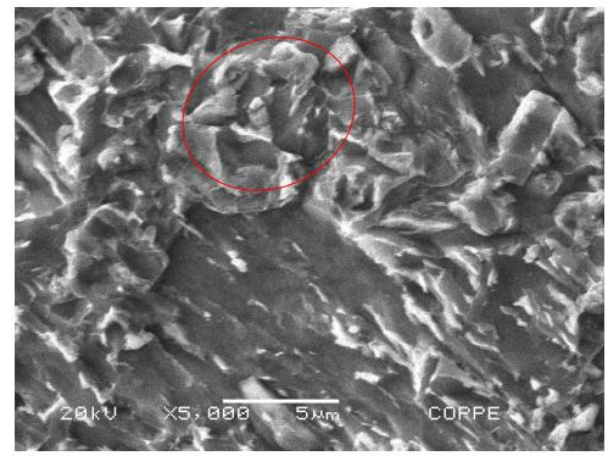

Figura 24 - ZGF da condição soldada com duas camadas de revestimento.

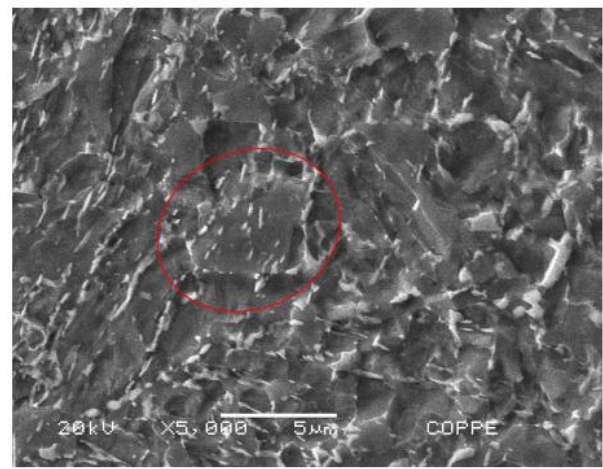

Figura 25 - bainita na ZGF da condição de duas camadas.

Já a ZIC, apresenta microestrutura de grãos alongados de ferrita com a presença de precipitados nos contornos de grãos, podendo-ser A-M, carbetos ou austenita retida tanto para uma quanto duas camadas (indicados por setas nas Figuras 26 e 27). 


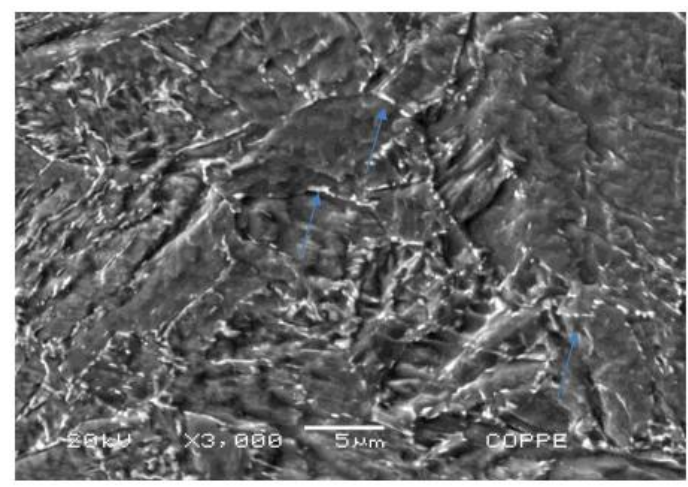

Figura 26 - ZIC da condição de uma camada.

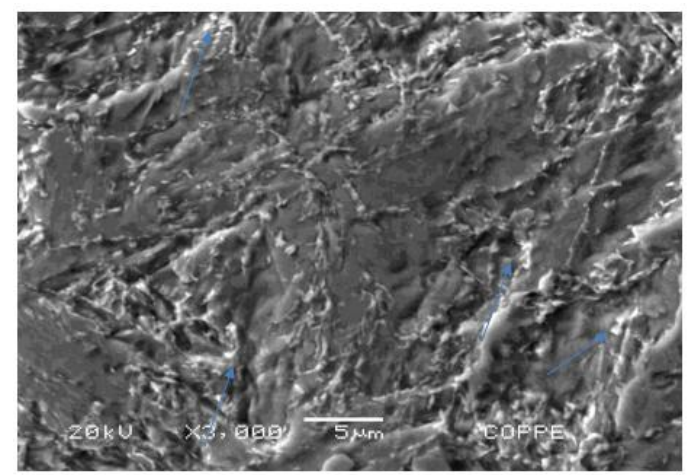

Figura 27 - ZIC da condição de duas camadas

No caso das amostras tratadas termicamente no campo intercrítico, na ZGG houve revenimento da martensita de ripas revertida em matriz ferrítica com partículas de microfases (em vermelho) precipitadas nos contornos de grãos, como austenita. Segundo as Figuras 28 e 29 , observa-se que o revenimento progride com o aumento da temperatura e tempo, gerando coalescimento e alinhamento de novas fases nos contornos de grãos ferríticos coalescidos da matriz.

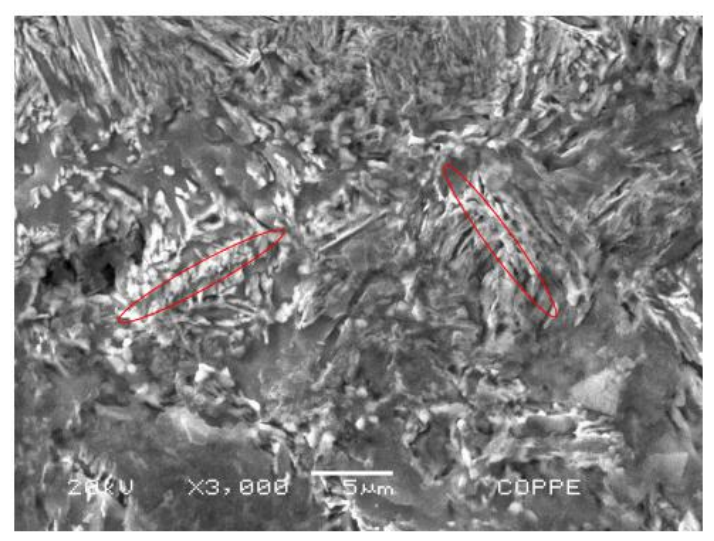

Figura 28 - ZGG da amostra $600^{\circ} \mathrm{C}$ por $4 \mathrm{~h}$ (1 camada). 


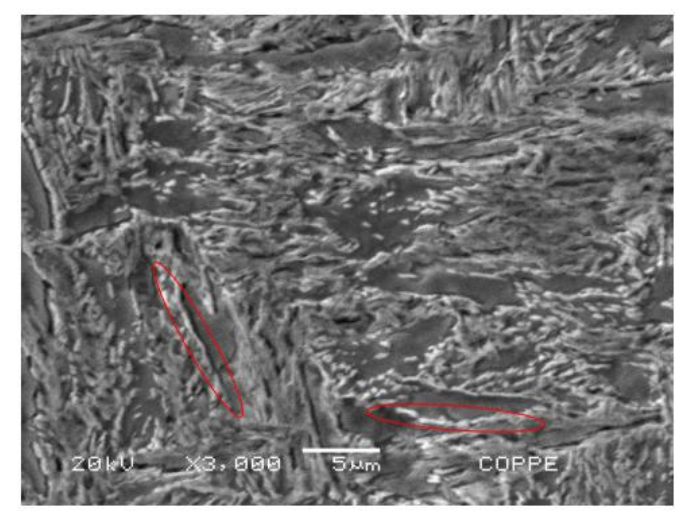

Figura 29 - ZGG da amostra $600^{\circ} \mathrm{C}$ por $4 \mathrm{~h}$ ( 2 camadas).

No caso da ZGF, com o progresso do tratamento, houve revenimento da martensita de ripas revertida grãos ferríticos (em vermelho) que sofreram crescimento, produzindo matriz ferrítica, bem como precipitação e coalescimeto de fases claras (em azul) nos contornos de grãos (provavelmente, austenita), refinando a microestrutura (Figuras 30 e 31).

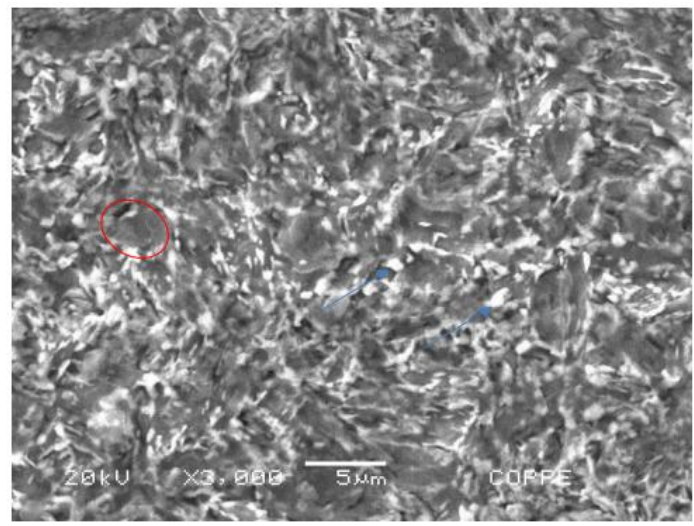

Figura 30 - ZGF da amostra $600^{\circ} \mathrm{C}$ por $4 \mathrm{~h}$ (1 camada).

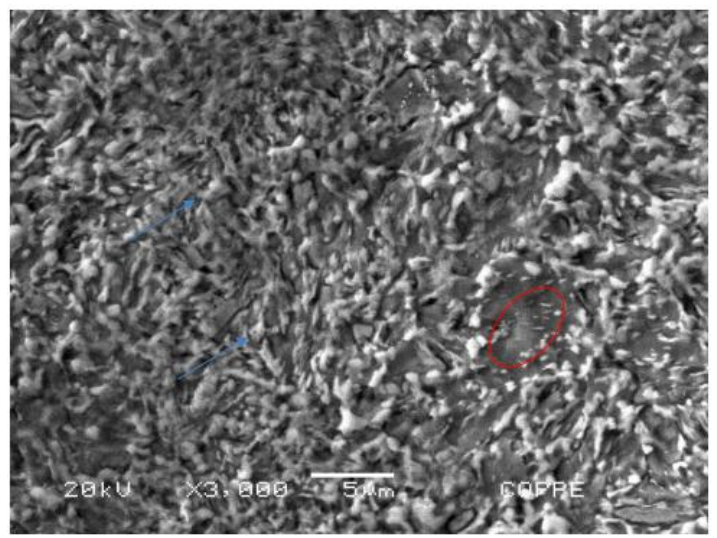

Figura 31 - ZGG da amostra $600^{\circ} \mathrm{C}$ por $4 \mathrm{~h}$ (2 camadas). 
Semelhantemente, na ZIC, houve a precipitação, coalescimento e alinhamento de fases claras, provavelmente, austenita (indicadas em vermelho) nos contornos de grãos da matriz ferrítica, refinando a microestrutura (Figuras 32 e 33 ).

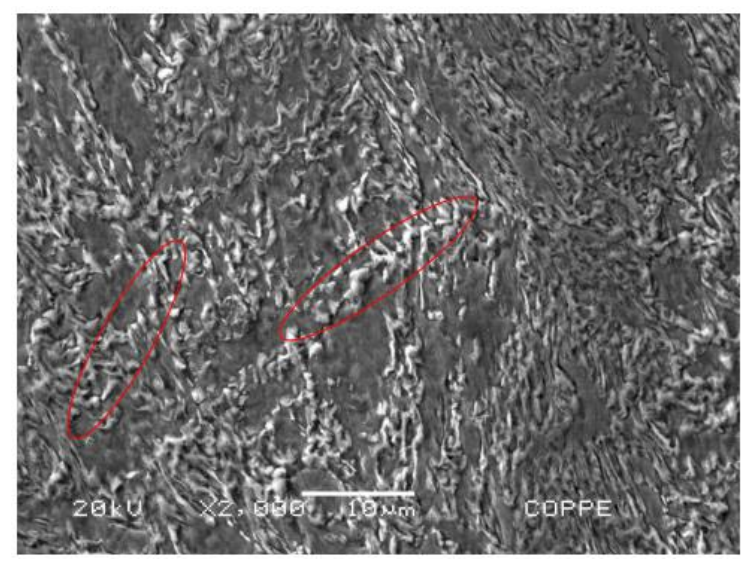

Figura 32 - amostra $600^{\circ} \mathrm{C}$ por $4 \mathrm{~h}$ (1 camada).

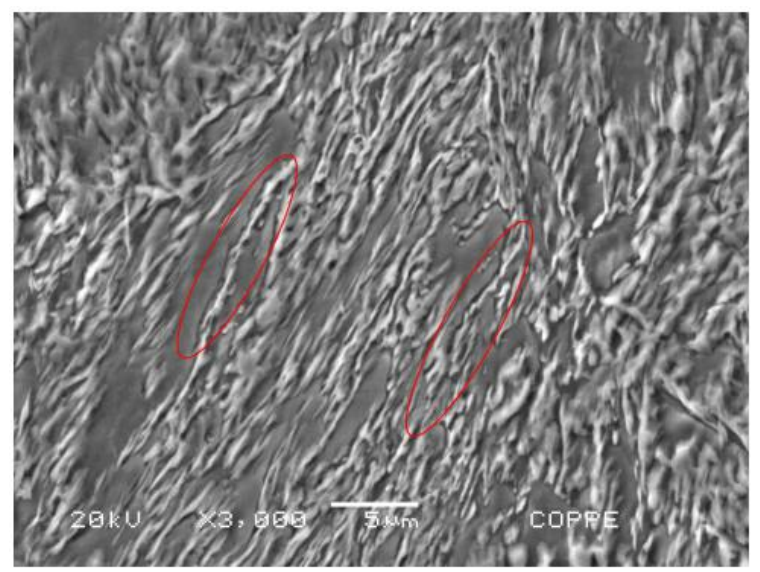

Figura 33 - ZIC da amostra $600^{\circ} \mathrm{C}$ por $4 \mathrm{~h}$ (2 camadas).

\section{CONCLUSÃO}

Segundo o diagrama de fases do sistema $\mathrm{Fe}-\mathrm{Ni}$, à $600^{\circ} \mathrm{C}$, as fases previstas são ferrita e austenita. Por isso, o estudo mostra que o tratamento térmico foi bastante benéfico no sentido de produzir fases mais dúcteis (ferrita) na região de grãos grosseiros em função do revenimento da martensita de ripas, permitir crescimento de grão ferrítico na zona de grãos finos e finalmente uma microestrutura mista de ferrita e bainita na zona intercrítica, principal responsável pela queda de dureza nesta condição. Vale ressaltar que na condição como soldada houve formação de constituintes AM que podem ser deletérios, os quais, porém, não foram identificados na condição tratada termicamente, outro benefício do tratamento térmico. 


\section{REFERÊNCIAS}

PASSOS, E. K. D., Estudo da Microestrutura da ZTA do Aço 9Ni Através da Soldagem com Dupla Camada, Universidade Federal do Rio de Janeiro, RJ, 2016

REDDO, A. M., Soldagem de Revestimento GTAW de Tubo de Aço 9\% Ni com Superliga de Níquel 625 e sua Posterior Soldagem de Topo com Diferentes Processos, Universidade Federal do Rio de Janeiro, RJ, 2015

RODRIGUES, C. R., Avaliação das Transformações de Fase do Aço com 9\% de Níquel e ds Zonas Termicamente Afetadas Simuladas in situ com Difração de Raios-x Síncroton, Universidade Federal Fluminense, RJ, 2016

ZEEMANN, A., EMYGDIO, G., 9\% Ni Steel Alloy for H2S Service. Rio de Janeiro: Nace International, 2014 